\title{
Implementation of M-Learning Applications using Web Services
}

\author{
Mohammed Najm Abdullah ${ }^{1}$, Sarah wahed ${ }^{2}$ \\ Computer Engineering Department, UOT, Iraq ${ }^{1}$ \\ University of Information Technology \&Communication ${ }^{2}$
}

\begin{abstract}
Education Technology, in the early stages, can modify the curriculum to meet the learning situations and student life. Alternatives to traditional educational methods also provides lectures and promote higher education. For example, the new technology eliminates the spatial and temporal constraints, students and teachers do not need to be in the same row, or even within the same region, to exchange information or educational material, but can be anywhere without impeding their work. Moreover, the reduced operating costs for schools and universities, where they can provide all subjects using cheap technology, through the mail this project screens, and the aim of our study: first, to understand the benefits of learning through mobile devices (learn mobile), and second, to provide analysis of principles and patterns of mobile design and interface and tactics to solve the mobile joint development problems, and the third, to produce a new learning of the application, based on the results of this study, which provides direct contact between students and teachers. In order to establish these contacts, forms poll view the applications that can host various questions with the answer choices. The use of opinion polls also can quickly gather student responses and display the results on mobile devices screens.
\end{abstract}

Keywords: M-learning, E-learning, Mobile application.

\section{INTRODUCTION}

The development of the communication and computer technologies in the last ten years turned the world into small village through the internet. Many educational institutions like schools and universities are using the modern technologies in the teaching and learning process through the establishment of E-learning. E-learning is a flexible and modern way to improve the education, which enable the students and learners to access the material with minimal cost and effort. Mobile learning is a new concept in e-learning field, it consider as a next generation of the e-learning [1]by using the mobile devices such as laptops, MP3 players and mobiles phones as a mean of studying. Mobile learning is focused on the learner to be mobile, and interacts with mobile technologies. The technologies of wireless communication such as IEEE 802.11, Bluetooth, and GPRS are used to develop the e-learning system like informal classroom and eSchoolbag system[2]. The importance of M-learning is in case of difficulties of attendance the teachers to their classroom and meeting directly with the students. Learning resources provides relying on multimedia materials which make the learning process easier and flexible as well encourage them to continue in learning. Moreover, M-learning is an effective way to deliver information to the remote societies and far area by means of the modern communication technologies. This new technology helping to overcome barriers of space and time, the difficulty of transportation or the difficulty to agree on a time, as well as the accumulation of experiences and provide educational or training material prepared by the institutions for those who wish learners thereby reducing the cost of education. The students can solve exercises and interact with their teacher and other students in the same field as well.

\section{LITERATURE SURVEY}

There are several researches deals with the subject of Elearning and M-learning. Some of these researches can be presented as follows:

Alamäki and Seppälä in (2003) [3] presented a study deals with mobile learning using (SMS), the study aimed to make sure teachers and students trained supervisors ability to exchange ideas on teaching methods through a mobile phone, the use of SMS messages and digital photos service as part of the oversight process. The results showed that the trainees have turned to the use of mobile devices Because of what is available in the use of relevant and useful and immediate. The results also demonstrated that the use of digital images, which sent.

Corlett et al. in 2005 [4]presented a study deals with mobile learning using another applications, this study aimed to assess the organizer mobile education is designed for use by university students, and their attitudes toward him.students take advantage of existing applications on mobile, As well as tools designed specifically for students to manage their learning using a personal digital assistant devices(PDAs).

K.D. Tamhane et al. in 2015 [5] presented the design of a mobile learning application used to help students in computer courses. This application is developed using Java language and depends on multimedia animation to 
Vol. 4, Issue 2, February 2017

create the pervasive learning environment. This used by web browsers. The services running on the server application can be used even in if the student is offline and run on specific ports which are the application identifiers, incorporate the real time e-learning with the social and the client needs to know the address of the server engineering concept. This application is consisting of two machine and the port to connect to the server. Although part, the first one is the tutorial part where the learning the client must know the server's address and port, the contents are place and in second part chat room is server does not need to know anything about the client's available for users.

Vera I. Toktarova et al. in 2015 [6] discussing the issue of m-learning in higher education, by introducing the benefits of using m-learning systems in the learning process in the universities. This article is presenting an m-learning system of programming application using Android platform.

Shanmugapriya M et. al. in 2014 [7] presented am mlearning application for a ubiquitous learning environment on $3 \mathrm{G}$ mobile devices, so it can offer an interactive learning opportunities. The ubiquitous learning environment develops more on context data than elearning.

\section{PROBLEM STATEMENT}

Since a lot of educated people and students to use mobile devices and use them for a long time, even when they attending lectures, led to adopt the idea of e-learning using the mobile communication devices. This idea can exploit the lost time to serve the learning process by developing an application helping both the students and the teachers in the teaching and learning process.

\section{RESEARCH OBJECTIVE}

The aim of this project is studying the advantages of $\mathrm{m}$ learning, as well grant an analysis of principles and patterns of mobile interface design, In this project a mobile application is developed using Android platform and improve it, this application will support distance learning and provide direct communication between students and their teachers through the Internet.

The application will permit any user to create a learning course. The owner of a course can add other users to his course. Also, he can share files with the course members, add announcements and create polls for them.

Based on the above, this study aimed to:

- Detect the degree of use of mobile learning devices by graduate students in the teaching-learning process.

- Detect the rate of use of mobile learning devices by graduate students in the teaching-learning process.

- Identify impediments to the use of mobile learning devices by graduate students at the University.

- Knowing the differences between the graduate students at the University of learning in the use of mobile applications due to the variables (specialty, age, academic level, and gender, and the rate of use).

\section{THE PROPOSED SYSTEM}

The architecture used in this work is client-server in order to establish the communication process, this architecture is similar to the one which is used in the HTTP protocol that address or port at the time of connection initiation. The client acts as the active device which makes the first move to establish the communication whereas the server passively waits for such a request from a client. Figure 1 shows the component view of the system. Although clientserver architecture is used, the server is used only for communication and storage. Users do not need extra information, as they can utilize all the application's functions from their mobile phone.

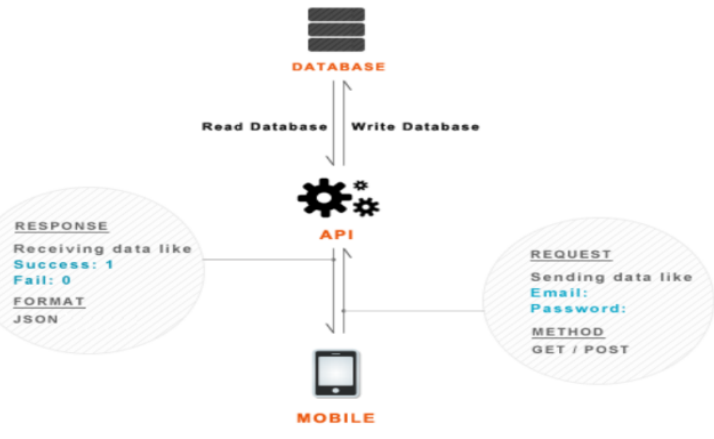

Figure 1: Component View of the System

\section{A. System Activities}

Activity is contains all classes that represent the application's activities (screens) and their operation. It is in charge of starting the application and uses the service package to establish the communication between the application's activities and the web server. Also it uses the manager package to manage its own data that are being produced while the application is running and runs operations that check the connection availability.

Account: account is a sub package of the activity and contains the classes that are in charge of sign in, register, change password, and change account name operations and activities. Each class which has the suffix Activity represents a screen of the mobile application. For example, LoginActivity.class and RegisterActivity.class are the login and register screens respectively.

In Figure 2 we can see a simple class diagram for the application.

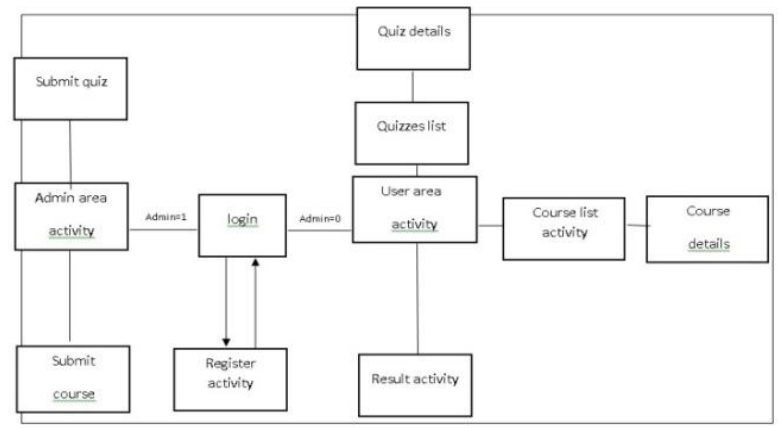

Figure2: Simplified Class Diagram 
Vol. 4, Issue 2, February 2017

\section{B. Database design and tables}

The database used in this application is MySQL which is built with in local host wamp server. Six tables are created which are; users, reset password, question, and quize, migration.

The database is created in the application and giving it a name and editing the security credentials. But before that, the database connection should be configured by editing the the lines of PHP code containing the credentials to match our database's credentials.

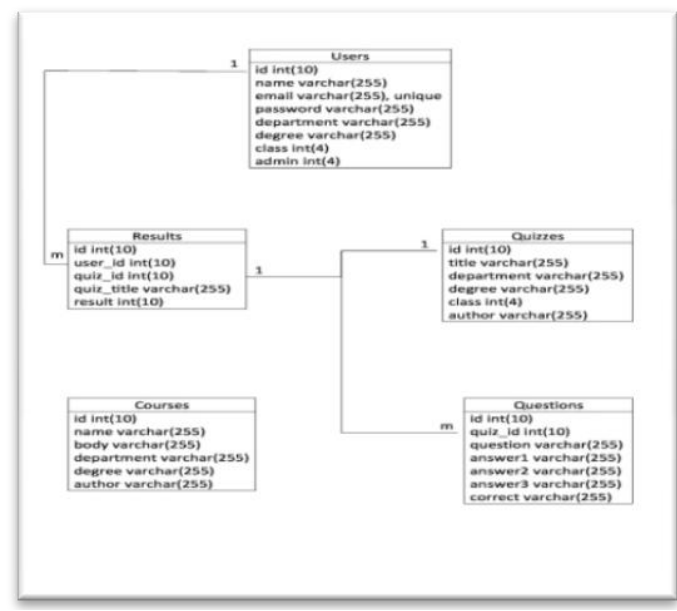

Figure 3: The entity-relation diagram of webserver's database

\section{System Interface}

The interface of this application is logging interface, where the student can enter his information if he / she registered before, and if not, the user can use the link in the screen to register and use the features of this application. The application provides two different interfaces for both students and professors In which they can interact with the system. See Figure 4.

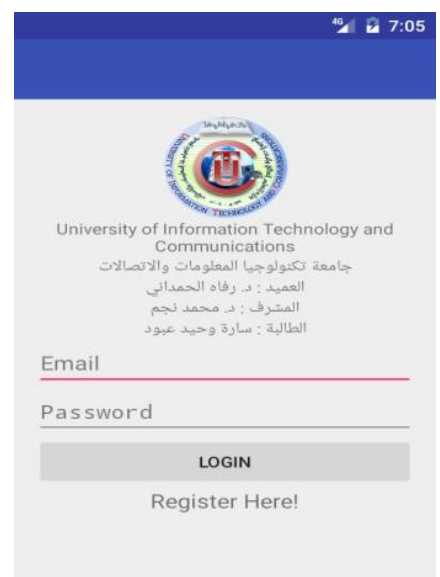

Fig. 4: Logging Interface

The professor's interface allows them to add new quiz for specific students by their department and degree using the SUBMIT QUIZ button, then enter two MCQ with the correct answer to be saved in the database for later use of student. See Figure 5.

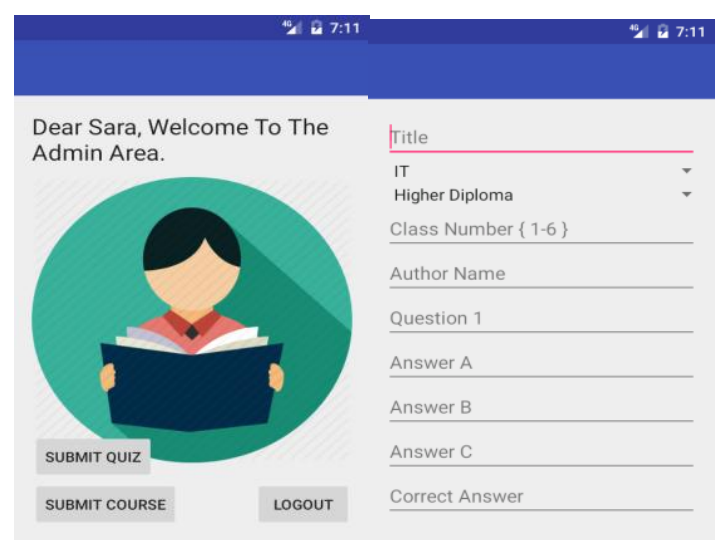

Fig. 5: Teacher's interface

The professor's can also add new course for specific students by their department and degree using the SUBMIT COURSE button, then enter the course details to be saved in the database for later use of student.

The student can click on anyone of the available quizzes, to take him/her to another interface that shows the questions, he/she can select the correct answers and click SUBMIT.

The Server will check the answers and give the result for the student at the same time.

The second feature for the student is the Courses, from which the student can show a list of courses that's available for his/her department, after clicking on a specific course title, the application will take him/her to a new interface and show all the details about the selected course.

\section{VI.CONCLUSION}

The project is studying the benefits of m-learning, to provide an analysis of principles and patterns of mobile interface design, and tactics that solve common mobile development problems. Lastly, its goal was to develop a mobile application for the Android platform that would provide functions which support distance learning and offer direct communication between students and their teachers through the internet.

The model allows to easily change the requirements when needed, and add more features and fix the bugs. This model is one of the best development model for developing an Android application, but it needs to be stressed that it requires experience in developing Android applications.

\section{FUTURE WORK}

The systems can be improved by adding some extra characteristics and new features. Here's some suggestion to future work:

- Deploying such system to schools and universities to facilitate mechanism learn. This makes to procedures easier learn.

- It is possible to add attach file multimedia and video . 
- All things considered, this work catches consideration and motivates designers, and developers to upgrade the learning and use to facilitate their learning in formal and informal settings and how these devices are used.

\section{REFERENCES}

[1] M. Sharples, Disruptive devices: mobile technology for conversational learning. International Journal of Continuing Engineering Education and Life Long Learning, 12(5/6), 2005, 504520.

[2] C. Chang , J. Sheu, Design and Implementation of Ad Hoc Classroom and eSchoolbag Systems for Ubiquitous Learning, Proc. of IEEE International Workshop on Wireless and Mobile Technologies in Education (WMTE 2002), 2007, (p. 8-14).

[3] P. Seppälä,, H. Alamäki, Mobile learning in teacher training. Journal of Computer Assisted Learning, 19, 2003, 330-335.

[4] D. Corlett, M. Sharples, Susan \& Chan, Evaluation of a mobile learning organiser for university students. Journal of Computer Assisted learning, 21, 2005, 162-170.

[5] K.D. Tamhane et al, Mobile learning application, International Journal of Scientific and Research Publications, Volume 5, Issue 3, March 2015.

[6] Vera I. Toktarova et al, Design and Implementation of Mobile Learning Tools and Resources in the Modern Educational Environment of University, Review of European Studies; Vol. 7, No. 8; 2015.

[7] Shanmugapriya $M$ et. al, Designing an m-learning application for a ubiquitous learning environment in the android based mobile devices using web services, Indian Journal of Computer Science and Engineering. 